\title{
Service differentiated drop code unit for metro ring optical networks
}

\begin{abstract}
The authors demonstrate using both simulation and experiment, a drop code unit for metro ring optical networks with service differentiation capability. This is achieved by means of a spectral amplitude coding technique whereby the code weight in a particular channel is varied to provide different signal quality levels. Transmission of three channels with different weights operating at $10 \mathrm{Gbps}$ per channel was simulated over a $68 \mathrm{~km}$ unamplified and 185 $\mathrm{km}$ amplified links of dispersion compensated fibre. Services are perfectly dropped at bit error rates from 10-9 to 10-3, leaving the through service free from accumulated noise. The authors also present a 2.5 Gbps per channel proof-of-concept experiment over $40 \mathrm{~km}$ of single-mode fibre (SMF).
\end{abstract}

